\title{
Study of referrals to department of psychiatry in tertiary care general hospital setting
}

\author{
Srilakshmi Pingali ${ }^{1}$, Ajay Kumar Joopaka ${ }^{2 *}$, Ravi Varma Jangam³ ${ }^{3}$ Umashankar $\mathbf{M}^{4}$ \\ ${ }^{\mathbf{1}}$ Associate Professor, ${ }^{\mathbf{2}}$ Assistant Professor, ${ }^{3}$ Junior Resident, ${ }^{4}$ Professor and HOD, Dept. of Psychiatry, Gandhi Medical College and \\ Hospital, Secunderabad, Telangana, India
}

*Corresponding Author: Ajay Kumar Joopaka

Email: drajaykmc@gmail.com

\begin{abstract}
Background: Study of referral pattern to psychiatry helps us to understand the type of patients and the rate of referral from individual departments. It also helps us to understand the need for consultation liaison services (CLP) thereby strengthening the General Hospital Psychiatric Units (GHPU)

Aim: To study the referral pattern to psychiatry in a tertiary care teaching hospital.

Materials and Methods: All referrals to the department of psychiatry for a period of two months were included in the study. Sociodemographic details, reasons for referral and the department from which referred were noted. The Psychiatric diagnosis was made according to the ICD -10 criteria. The overall referral rate to psychiatry and referral from individual departments was noted and descriptive statistics was applied to represent the same.

Results: The overall referral rate to psychiatry was found to be $1.17 \%$ with majority being from medical specialities $(62 \%)$. The most common reasons for referral have been suicidal attempts and most common psychiatric disorder diagnosed among referred has been delirium.

Conclusion: The low levels of referrals to psychiatry emphasize the need for better consultation liaison services.
\end{abstract}

Keywords: Referrals, Consulatation-liasion, General hospital psychiatric units.

\section{Introduction}

Psychiatry has come a long way as a medical discipline, despite the challenges posed by stigma and superstition. ${ }^{1}$

The evolution in the understanding of mental illness is shown by the fact that the treatment setups for patients with mental illness has changed from asylums, to mental institutes and finally to general hospital psychiatry units. Perhaps accepting the fact that mental illness like any other illness needs treatment in a general hospital and that the people with medical illnesses have comorbid mental illness requiring psychiatric intervention. The need for consultation and liaison with other departments has come into sharp focus after the establishment of the general hospital psychiatry units.

The purpose of consultation and liaison is to integrate all information available from all the sources to provide optimal health care in a way that is sensitive to the needs of patients and other specialists. ${ }^{2}$

Psychiatric units in the general hospitals have increased opportunities for such consultation liaison services. The role of a psychiatrist in such hospitals is manifold.

Treating patients with psychiatric disorders who have been admitted for the treatment of medical problems, managing patients with medically unexplained physical symptoms or managing patients presenting with acute psychiatric symptoms as a result of an underlying medical condition, all come under the purview of the psychiatrist. A consultation liaison psychiatrist therefore plays multiple roles and it is on him that rests the onus of bringing in awareness in staff of other departments regarding psychiatric disorders by utilising the opportunity during consultation and liaison. Thereby he is a clinician, collaborator, researcher, administrator and teacher. ${ }^{3}$

Despite the high prevalence of comorbid psychiatric disorders in medical conditions, the rate of referral to psychiatry has been low. For instance, the prevalence of depression in medical outpatients in a study done in India was found to be $30 \% .^{4}$ The prevalence of psychiatric morbidity in postoperative patients was found to be around $27 \% .^{5}$

However, the overall rate of referral to psychiatry in India has been shown to be between $0.06 \%$ to $3.6 \%{ }^{6}$

A Study conducted in Telangana in a rural teaching hospital showed the referral rate to be $0.18 \%$, of which the referral from medicine and allied branches was $75.7 \%$ and surgery and allied branches was 24.3\%. ${ }^{1}$ Another study conducted in Delhi showed the referral from medicine and allied branches to be $58.46 \%$ and surgery and allied branches to be $14.6 \% .^{7}$

We undertook the study to understand the referral rate and pattern of referrals in our hospital to the department of psychiatry, which is a tertiary referral centre in the state of Telangana. The study was done for a period of two months from March $1^{\text {st }}$ to April $30^{\text {th }} 2019$.

\section{Aims and Objectives}

Aim

To study the pattern of referrals to the department of psychiatry.

\section{Objectives}

To study the sociodemographic profile, clinical characteristics and common causes for referral to psychiatry To estimate the referral rate to the department of psychiatry.

\section{Materials and Methods}

The study was a cross sectional study, done in an 1800 bedded tertiary care referral centre cum teaching hospital in Telangana. The hospital has medical and surgical specialities 
and their allied branches to which patients from all over the state visit or are referred.

All the in-patients referred to psychiatry from the other departments of the hospital between March1st to April 30 2019 willing to give written informed consent and accompanied by a reliable informant were taken in for the study. They were administered a semi-structured proforma which included details of socio demographic features and profile of referrals consisting of source, reason for referral and department from which referred. Psychiatric diagnosis was made as per ICD-10 criteria. A total of 140 patients were included in the study by a method of convenience sampling.

\section{Statistical analysis}

Descriptive analysis was computed in terms of mean and standard deviation for continuous variables $\&$ frequency with percentage for ordinal and nominal variables. The Statistical package for social sciences version 25 (IBM $^{\circledR}$ SPSS $^{\circledR}$ Statistics, New York, United States).

\section{Results}

A total of 140 inpatients were referred to the department of psychiatry over a period of two months between $1^{\text {st }}$ March to $30^{\text {th }}$ April 2019, out of the total 12000 patients admitted in the hospital during this period yielding a referral rate of $1.17 \%$.

Table 1: Sociodemographic variables

\begin{tabular}{|c|c|c|}
\hline $\begin{array}{l}\text { Sociodemographics } \\
\text { characteristics }\end{array}$ & $\mathrm{N}=140$ & $\begin{array}{c}\text { Percentage } \\
(\%)\end{array}$ \\
\hline Age & $\begin{array}{l}\text { Mean: } 35.30 \\
\text { S.D: } 13.46\end{array}$ & \\
\hline \multicolumn{3}{|l|}{ Gender } \\
\hline Male & 92 & 65.7 \\
\hline Female & 48 & 34.3 \\
\hline \multicolumn{3}{|l|}{ Religion } \\
\hline Hindu & 119 & 85 \\
\hline Muslim & 15 & 10.7 \\
\hline Christian & 6 & 4.2 \\
\hline \multicolumn{3}{|l|}{ Residence } \\
\hline Rural & 75 & 53.6 \\
\hline Urban & 65 & 46.4 \\
\hline \multicolumn{3}{|l|}{ Education } \\
\hline Professional & 1 & 0.7 \\
\hline Degree & 13 & 9.3 \\
\hline Inter & 17 & 12.1 \\
\hline High school & 26 & 18.6 \\
\hline Primary & 30 & 21.4 \\
\hline Illiterate & 53 & 37.9 \\
\hline \multicolumn{3}{|l|}{ Occupation } \\
\hline Professional & 2 & 1.4 \\
\hline Semi professional & 4 & 2.9 \\
\hline Clerk & 63 & 45.0 \\
\hline Skilled worker & 3 & 2.1 \\
\hline Semiskilled & 28 & 20.0 \\
\hline Unskilled & 40 & 28.6 \\
\hline Unemployed & & \\
\hline
\end{tabular}

\begin{tabular}{|l|c|c|}
\hline Socioeconomic status & & \\
\hline Low & $\mathbf{1 3 3}$ & $\mathbf{9 5}$ \\
\hline Middle & 4 & 2.9 \\
\hline Upper & 2 & 1.4 \\
\hline
\end{tabular}

The socio demographic features are summarized in Table 1. Most of the referrals were in the age group of 25-35 years, majority were males $(65 \%)$ and Hindu by religion $(85 \%)$ and residing in rural areas $(53.6 \%)$. Most of the patients were illiterate $(37.9 \%)$, unemployed $(30 \%)$ and belonged to low socio economic status $(95 \%)$.

Table 2: Reason for referral

\begin{tabular}{|l|c|c|}
\hline Disorders & Frequency & Percentage \\
\hline Alcohol related disorders & 42 & 30.0 \\
\hline $\begin{array}{l}\text { Attempted suicide with } \\
\text { poisoning }\end{array}$ & 46 & 32.9 \\
\hline Sleep disorders & 11 & 7.9 \\
\hline Altered behaviour & 7 & 5.0 \\
\hline Head injury & 11 & 7.9 \\
\hline Psychiatric illness & 5 & 3.6 \\
\hline Others & 18 & 12.9 \\
\hline Total & 140 & 100.0 \\
\hline
\end{tabular}

On analysis of the reason for referral, most common reason was for evaluation of attempted suicide due to poisoning 46 $(32.85 \%)$, followed by alcohol related disorders $42(30 \%)$. Others included referrals for sleep disturbances, altered behaviour, or simply as psychiatric illness without elaborating the symptoms. (Table 2)

Table 3: Departmental referral

\begin{tabular}{|l|c|c|}
\hline Department & Frequency & Percentage \\
\hline Medicine and allied & 87 & 62.1 \\
\hline Surgery and allied & 53 & 37.9 \\
\hline
\end{tabular}

Most of the referrals were done from the department of general medicine and allied branches (62.1\%) followed closely by surgery and allied branches (37.9\%) (Table 3)

Table 4: Distributions of psychiatric disorders

\begin{tabular}{|l|c|c|}
\hline Psychiatric disorders & Frequency & Percentage \\
\hline Delirium & 51 & 36.4 \\
\hline Depression & 17 & 12.1 \\
\hline Psychosis & 9 & 6.4 \\
\hline Intentional self-harm & 25 & 17.9 \\
\hline Others & 10 & 7.1 \\
\hline No diagnosis & 28 & 20.0 \\
\hline Total & 140 & 100.0 \\
\hline
\end{tabular}

Of the 140 patients, a psychiatric diagnosis could be made in $112(80 \%)$. The most common being delirium 51(36.4\%) followed by intentional self-harm 25(17.8\%), depression $17(12.1 \%)$. 


\section{Discussion}

In the present study the referral rate to the department of psychiatry was $1.17 \%$. General medicine and allied branches accounted for $62.1 \%$ and surgical and allied branches for $37.9 \%$.

Referral rates in India have ranged between 0.06 to $3.6 \%{ }^{6}$

Studies as early as 1998 have shown the referral rate to be $0.65 \%$ with $45 \%$ of referrals from medical specialities and $22 \%$ from surgical specialities. ${ }^{8}$

Mean age of patients referred in our study was 35.30 years. Western studies have reported more number of geriatric referrals. ${ }^{9}$ The rate of referral in the geriatric group in our study was $6.3 \%$ in keeping with others studies from India which have reported similar referral rates for geriatric patients(3.3\%), possibly due to low awareness of geriatric mental health issues. ${ }^{10}$

Despite the high psychiatric comorbidity in medical and surgical patients $s^{4.5}$ the referral rate to psychiatry has been low. In order to understand the reasons behind the low rate of referral, non-psychiatric clinicians were assessed in a study about their referral to psychiatry. Majority of those assessed felt that less than $20 \%$ of their patients had psychiatric problems and of these only $25 \%$ were sent for psychiatric referral. In the same study it was seen that about two thirds of clinicians referred their patients if they felt they would benefit from them, however $29 \%$ referred only when patients were over complaining. On being asked about their patients' response to psychiatry referral, half of the treating physicians felt that though the patients agreed, they didn't always keep the psychiatrist's appointment. Whereas the other half felt that the patients agreed reluctantly. ${ }^{11}$ Some studies have shown that, of the patients referred to psychiatry, 93.7\% actually went for the review which led the authors to conclude that the systemic and referrer factors played a major role rather than the patient factors. ${ }^{12}$

In a country wide online survey of 90 centres in India the most common diagnostic categories that were referred to psychiatry were delirium, substance use disorders, self-harm, and depression. ${ }^{13}$

Our study findings were in keeping with the above findings and the most common psychiatric diagnosis established according to ICD-10 criteria in our study was delirium $36.4 \%$, followed by intentional self-harm $17.9 \%$. This was followed by depression and psychosis. Majority of the underlying diagnosis of delirium was alcohol withdrawal.

A study conducted in Delhi reported higher number of neurotic disorders compared to our study. ${ }^{7}$ The reason for low referral could possibly be attributed to the less dramatic presentation of these cases thereby missing the eye of the primary physician and also because only inpatient referrals were studied.

In our study when individual reasons for referral were studied, the most common reason for referral has been suicidal attempt (32.9\%). No attempt was made by the referring physician to distinguish between suicidal and nonsuicidal self-injury. Previous studies have shown attempted suicide, especially those with pesticide poisoning and hanging to be most frequently referred. ${ }^{12}$ The possible reason behind this maybe that the patients with attempted suicide are stabilized in the department of medicine and subsequently referred to department of psychiatry. Studies on intentional self-harm have also shown that majority patients attempting self-harm being referred to psychiatry, however they did not qualify for any previous psychiatric diagnosis nor met any criteria for the same after the injury. ${ }^{14}$ In our study also $17.9 \%$ were diagnosed as intentional self-harm as per ICD 10 -X 6084 , not meeting criteria for any other psychiatric diagnosis.

Alcohol related disorders were another common reason for referral in our study (30\%) and delirium could be diagnosed in $36.4 \%$ of the referred patients. Other studies in Telangana also reported most common reason for referral to be acute onset of altered sensorium. ${ }^{1}$ Other studies on delirium have shown that the average delay for psychiatry referral was 2.36 days. The factors that were associated with a delay in referral were sleep disturbances, motor retardation, admission in intensive care unit and absence of a past history of psychiatric disorders. ${ }^{15}$ These factors are important to understand, as addressing these would prevent unnecessary delay in diagnosis.

The referral rate to psychiatry needs to improve and in order to do so the consultation liaison services also need to improve. In fact studies done on non-psychiatrist clinicians showed that majority (87\%) of the doctors believed that they would have been helped if their undergraduate medical training in psychiatry would have been better along with other measures like running of joint clinics and opening consultation liaison psychiatry units..$^{9}$ This in turn would reduce the negative perceptions around psychiatry, as surveys have shown that doctors from other disciplines have negative perception about psychiatric ailments such as drug addiction, eating disorders, depression, dementia, and schizophrenia. ${ }^{16}$

Studies done on the prevailing facilities of consultation liaison services in India have shown that majority have an oncall service provided. It was shown however that the more effective model was the hybrid model where a psychiatrist is available in the emergency department. This showed that not only the number of referrals for psychiatric disorders improved, but also the medical disorders having comorbid psychiatric illnesses. ${ }^{17}$

Therefore strengthening consultation liaison services by running joint clinics and conducting interdepartmental seminars, training of staff to detect psychiatric disorders early and finally increasing exposure to psychiatry in undergraduate training will go a long way not only to increase knowledge about psychiatric illnesses but also improve referrals to psychiatry, thereby ensuring a holistic treatment of the patients.

\section{Conclusion}

The low rate of referral in our study has highlighted the need for extensive consultation liaison service.

\section{Limitation and Future Directions}

A small sample size, study of exclusive inpatient referrals and short duration of study have been our major limitations. 
Further study into the knowledge and awareness of the physicians of psychiatric disorders and evaluation of various factors causing delay in diagnosis, would help us to understand the reasons for poor referral rate and advocate remedial measures accordingly.

\section{Source of Funding}

None.

\section{Conflict of Interest}

None.

\section{References}

1. Vishwak Reddy V, Anil V, Datt. Referral to Psychiatry in a Rural Teaching Hospital. J Basic Clin Res. 2016;3(2):11-7.

2. Lipowski ZJ. Review of consultation psychiatry and psychosomatic medicine. I. General principles. Psychosom Med. 1967;29:153-71.

3. Grover S, Avasthi A. Consultation- liaison psychiatry in India: Where to go from here?. Indian J Psychiatry. 2019;61:117-24.

4. Kohli C, Kishore J, Agrawal P, Singh SV. Prevalence of unrecognised depression among outpatient department attendees of a rural hospital in Delhi, India. J Clin Diagn Res. 2013;7(9):1921-5.

5. Ajmal IT, Babu EPK, Baskaran R, Prashaanth. A study on the prevalence of psychiatric morbidity in postoperative patients who have undergone major abdominal surgeries. M.K. J Dent Med Sci. 2017;16(3):57-8.

6. Grover S. State of Consultation-Liaison Psychiatry in India: Current status and vision for future. Indian J. Psychiatry. 2011;53:202-13.

7. Kumar P, Srivastava S, Bhatia MS. A study of psychiatric referrals in a multidisciplinary teaching hospital. DPJ. 2009;12(2).

8. Avasthi A, Sharan P, Kulhara P, Malhotra S, Varma VK. Psychiatric profiles in medical-surgical populations: need for a focused approach to consultation-liaison psychiatry in developing countries. Indian J Psychiatry. 1998;40(3):224-30.
9. Wallen J, Pincus HA, Goldma HH, Marcus SE. Psychiatric consultations in short term general hospitals. Arch Gen Psychiatry. 1987;44(2):163-8.

10. Bhogale GM, Katte RM, Heble SP. Psychiatric referrals in multispeciality hospital. Indian J Psychiatry. 2000;42(2):18894.

11. Chadda RK, Shome S. Psychiatric aspects of clinical practice in general hospitals: A survey of non-psychiatric clinicians. Indian J Psychiatry. 1996;38:86-92.

12. Hashim U, Kumar RS, Philip M. Consultation-liaison psychiatric service utilization by suicide attempters. Indian $J$ Psychiatry. 2018;60:427-32.

13. Grover S, Sarkar S, Avasthi A, Malhotra S, Bhalla A, Varma SK. Consultation-liaison psychiatry services: Difference in the patient profile while following different service models in the medical emergency. Indian J Psychiatry. 2015;57(4):361-6.

14. Das PP, Grover S, Avasthi A, Chakrabarti S, Malhotra S, Kumar S. Intentional self-harm seen in psychiatric referrals in a tertiary care hospital. Indian J Psychiatry. 2008;50(3):18791.

15. Grover S, Kate N, Mattoo SK, Chakrabarti S, Malhotra S, Avasthi A, Kulhara P, Basu D. Delirium: Predictors of delay in referral to consultation liaison psychiatry services. Indian $J$ Psychiatry. 2014;56(2):171-5

16. Challapallisri V, Dempster LV. Attitude of doctors towards mentally ill in Hyderabad, India: Results of a prospective survey. Indian J Psychiatry. 2015;57:190-5.

17. Grover S, Avasthi A. Consultation-liaison psychiatry services: A survey of medical institutes in India. Indian J Psychiatry 2018;60:300-6.

How to cite this article: Pingali S, Joopaka AK, Jangam RV, Umashankar M. Study of referrals to department of psychiatry in tertiary care general hospital setting. Telangana J Psychiatry. 2020;6(2):166-169. 